\title{
Trajectory of thirst intensity and distress from admission to 4-weeks follow up at home in patients with heart failure
}

This article was published in the following Dove Press journal:

Patient Preference and Adherence

\author{
Nana Waldréus' \\ Misook L Chung ${ }^{2}$ \\ Martje $\mathrm{HL}$ van der Wal ${ }^{3,4}$ \\ Tiny Jaarsma ${ }^{5,6}$ \\ 'Department of Neurobiology, \\ Division of Nursing, Care Sciences \\ and Society, Karolinska Institutet, \\ Huddinge, Sweden; ${ }^{2}$ College of \\ Nursing, University of Kentucky, \\ Lexington, KY, USA; ${ }^{3}$ Department \\ of Social and Welfare Studies, \\ Division of Nursing Science, Faculty \\ of Medical and Health Sciences, \\ Linköping University, Linköping, \\ Sweden; ${ }^{4}$ Department of Cardiology, \\ University Medical Center Groningen, \\ University of Groningen, Groningen, \\ the Netherlands; ${ }^{5}$ Department \\ of Social and Welfare Studies, \\ Division of Nursing Science, Faculty \\ of Medical and Health Sciences, \\ Linköping University, Linköping, \\ Sweden; ${ }^{\circ}$ Mary McKillop Institute for \\ Health Research, Australian Catholic \\ University, Melbourne, VIC, Australia
}

Background: Patients with heart failure (HF) can suffer from increased thirst intensity and distress. Trajectories of thirst intensity and distress from hospital to home are unclear. The aim of this study was to describe thirst intensity and distress trajectories in patients from the time of hospital admission to 4 weeks after discharge, and describe trajectories of thirst intensity and distress by patients' characteristics (gender, age, body mass index [BMI], plasma urea, anxiety, and depression).

Patients and methods: In this observational study, data were collected from patients with HF $(n=30)$ at hospital admission, discharge, and at 2 and 4 weeks after discharge. Thirst intensity (visual analog scale, $100 \mathrm{~mm}$ ) and distress (Thirst Distress Scale-HF, score 9-45) were used. Trajectories were examined using growth modeling.

Results: Trajectory of the thirst intensity was significantly different, for patients with low and high thirst intensity levels (median cut-off $39 \mathrm{~mm}$ ), from admission to 4 weeks follow up (thirst increased and decreased, respectively). Patients with high level of thirst distress (median score $>22$ ) at admission, having fluid restriction and women continued to have higher thirst distress over time. Patients feeling depressed had higher thirst intensity over time. There were no differences in the trajectories of thirst intensity and distress by age, BMI, plasma urea, and anxiety.

Conclusion: Intensity and distress of thirst, having fluid restriction, and feeling depressed at the admission were critical in predicting the trajectory of thirst intensity and distress after discharge to home in patients with HF. Effective intervention relieving thirst should be provided before their discharge to home.

Keywords: heart failure, thirst intensity, thirst distress, trajectories, fluid restriction

\section{Introduction}

Thirst can be a troublesome symptom in patients with heart failure (HF). ${ }^{1-9}$ Nineteen percent of HF patients have persistent thirst. ${ }^{8}$ Patients with $\mathrm{HF}$ are most likely to have thirst that comes and goes, but once thirst occurs, there is a risk that it will emerge again at a later time. ${ }^{8}$ Thirst is the subjective sensation of a desire to drink water that cannot be ignored, and it can be measured as intensity and distress. ${ }^{1,10}$ Thirst intensity is defined as the severity or the strength of thirst, and thirst distress is the degree to which the patient is bothered by thirst or its associated discomfort. ${ }^{1,11}$ Given the $\sim 26$ million patients with HF worldwide, ${ }^{12}$ thirst can be seen as an important health issue that can adversely affect patients' quality of life. , $^{1,213,14}$

Research shows that having a fluid restriction, higher body mass index (BMI), higher plasma urea, being younger and feeling anxiety, and depressive symptoms are
Correspondence: Nana Waldréus Department of Neurobiology, Care Sciences and Society, Karolinska Institutet, Alfred Nobels Alle' 23, Huddinge 14183, Sweden

Tel +4685248376I

Fax +46 I930360।

Email nana.waldreus@ki.se 
associated with increased thirst in patients with HF. ${ }^{1,8,9,13-16}$ In a previous cross-sectional study, it was found that very intensive thirst was experienced in patients with worsening HF admitted to an emergency hospital. ${ }^{7}$ However, there is limited knowledge about whether thirst experience changes from admission to after hospital discharge, and whether their thirst experience is associated with patient characteristics. Therefore, the aim of this study was to describe trajectories of thirst intensity and distress in patients with HF, from the time of hospital admission to 4 weeks after discharge. The specific objectives were as follows: (a) examine whether trajectories of thirst intensity and distress differ between patients who experienced high and low levels of thirst intensity and distress at the time of hospital admission, and (b) examine whether trajectories of thirst intensity and distress are different by patients' characteristic factors, such as gender, fluid restriction, age, BMI, plasma urea, anxiety, and depression. These potential demographic, clinical, and psychological factors were selected based on previous studies that reported significant associations with thirst experience..$^{1,8,9,13-16}$

\section{Methods}

A prospective observational study was conducted between January 2012 and August 2014. The Regional Ethics Committee Stockholm approved the study (2011/232-31/1), and all patients provided written informed consent before participation. The study complied with the Declaration of Helsinki.

\section{Sample and setting}

Patients $>60$ years of age who were admitted to the hospital due to worsening HF, with a left ventricular ejection fraction (LVEF) of $\leq 50 \%$, were included. Patients were excluded if they had either of the following conditions or other diseases that carry a risk of increased thirst (eg, pulmonary disease with oxygen treatment and insulin-treated diabetes). They were also excluded if they had difficulty understanding or reading the Swedish language, a hospital stay $<24$ hours, or patients who could not communicate due to severe HF and thus, could not answer any questions. The study was performed at the Department of Internal Medicine at a midsized hospital in Sweden.

\section{Procedure}

A research nurse recruited patients from the Department of Internal Medicine during the daytime, within 24 hours after admission to the hospital. Data were collected at the time of hospital admission, at the time of hospital discharge, and
2 and 4 weeks after discharge to the patients' home, by the research nurse. The time point of data collection at admission was included based on previous results about increased thirst in patients with HF at hospital admission. ${ }^{7}$ Participants completed questionnaires, including thirst intensity and distress, feelings of anxiety and depression, and demographics. The research nurse collected clinical characteristics by medical chart review. Patients were also asked to provide blood samples immediately after responding to the questionnaires.

\section{Measurements}

A visual analog scale (VAS) was used to assess the sensation of thirst intensity at the moment of questioning. This scale has been previously validated and used to assess thirst intensity in patients with HF. ${ }^{7-9,14-17}$ The patients were asked to place a cross-mark on a line $(100 \mathrm{~mm})$ to grade their thirst intensity from none $(0 \mathrm{~mm})$ on the left side, to the worst possible level $(100 \mathrm{~mm})$ on the right side.

The Thirst Distress Scale for patients with HF (total score 9-45) was used to measure the thirst distress perceived by the patients during the preceding 3 days. ${ }^{18}$ This scale consists of 9 items, rated from 1 (strongly disagree) to 5 (strongly agree). The scale is a valid and reliable tool for evaluating thirst distress in patients with HF. ${ }^{9,18,19}$ In this study, the Cronbach's $\alpha$ was 0.85 .

In this study, patient factors associated with thirst included gender, age, fluid restriction, BMI, plasma urea, anxiety, and depression. Data on age and gender were collected using a structured sociodemographic questionnaire. Information about prescribed fluid restriction was collected by asking the patients whether or not they restricted their fluids, and the volume of the prescribed restriction was recorded. BMI was calculated by weight $(\mathrm{kg}) /$ length $\left(\mathrm{m}^{2}\right)$. Blood samples were analyzed for plasma urea (coefficient of variation $6 \%$; DXC800, Beckman-Coulter, Brea, CA, USA) at the Study Center, Karolinska University Laboratory, Stockholm, Sweden. We also collected the symptom severity of HF, the New York Heart Association (NYHA) functional classification, the LVEF, plasma N-terminal prohormone brain natriuretic peptide (NT-proBNP, ng/L), plasma creatinine $(\mu \mathrm{mol} / \mathrm{L})$, serum osmolality (mosmol $/ \mathrm{kg})$, and duration of hospitalization to describe patients' characteristics.

We assessed being anxious (experiencing worry or nervousness) and depressed (a state of unhappiness or despondence) using a 5-point Likert scale (1= strongly disagree to $5=$ strongly agree) in past 3 days. Although many standardized instruments for assessing anxiety and depression are available, most instruments assess experience of 
such psychological distress in past 2 weeks to 4 weeks that may be not sensitive to capture the association with their thirst experience in past 3 days in this study. We assessed face validity of the 2 questions of being anxious and being depressed in patients with HF before we used the items in this study. Internal consistency of the items was satisfactory (Cronbach's $\alpha$ 0.79). In this study, patients who scored $\geq 3$ on a 5-point Likert scale were considered to be experiencing moderate-to-severe anxiety or depression.

\section{Data analysis}

Descriptive statistics (mean [SD], median [interquartile range, IQR], or frequency [\%]) were used to describe the study samples' demographic and clinical characteristics. Before we conducted growth modeling analysis, we dichotomized patients into low and high thirst intensity groups at the time of admission using the median VAS of $39 \mathrm{~mm}$ as a cutpoint. Patients with a score of $\leq 39$ were the low thirst intensity group, and $>39$ were the high thirst intensity group. Patients were also dichotomized into low and high thirst distress groups by using the median score of 22 from the Thirst Distress Scale at admission.

We grouped patients into 2 groups at hospital admission based on patient factors using mean (SD) or median (IQR) based on their distribution. For example, patients were grouped into young and old age groups, and high and low BMI groups using mean values of age ( $81 \pm 7$ years) and BMI $\left(26 \pm 6 \mathrm{~kg} / \mathrm{m}^{2}\right)$, and high and low plasma urea groups using median (IQR) value $(9,8-12 \mathrm{mmol} / \mathrm{L})$. Patients were categorized into being anxious and depressed using the score $\geq 3$, and into absence or presence of fluid restriction groups using their self-report.

For this study, we were interested in evaluating thirst intensity and distress during hospitalization and after discharge to home. Growth modeling was used to identify trajectories of thirst intensity and distress over time. ${ }^{20,21}$ Growth modeling is a way of analyzing repeated-measures data that have a hierarchical structure in regression. ${ }^{20}$ The advantages with growth modeling are that it measures growth throughout, not just at the end of the study, and provides intercept and estimate to calculate the rate of growth. ${ }^{20-22}$ The intercept is thirst (intensity or distress) of each participant at the initial point, which was the admission time in this study, and the estimate (ie, unstandardized B) indicates slope. If the $P$-value of interaction between time and group is $<0.05$, it indicates a significant trajectory of thirst intensity and distress between 2 groups over time (ie, from admission to 4 weeks after discharge). Estimates with 95\% CIs were calculated for each growth model. A $P$-value of $<0.05$ was considered significant. All data were analyzed with the Statistical Package for Social Sciences version 22 (SPSS, Chicago, IL, USA).

\section{Results \\ Sample characteristics}

Of the 119 patients with worsening HF who were screened at the time of hospital admission, the majority were excluded because of difficulty with the Swedish language $(n=27)$ or due to severe HF congestion $(n=20)$. Another 27 patients were excluded due to other exclusion criteria (Figure 1). Fifteen patients declined to participate. A total of 30 patients were included in this study and 3 were lost to follow-up due to severe illness at discharge, while 2 were lost after 2 weeks of follow-up (Figure 1). Patients who were lost to follow-up ( $n=5,2$ men and 3 women) had lower LVEF (mean 23\%), longer hospital stay (median [IQR], days 8 [3-17]), and higher median NT-proBNP $(11,000$ [5,365-21,300] ng/L) than patients who completed the study. Their mean age (years 79 \pm 8 ), median thirst intensity (VAS 43 [8-65] mm), and thirst distress (scores 22 [17-42]) were similar to those who completed the study.

\section{Patients admitted for worsening HF $\mathrm{N}=119$}

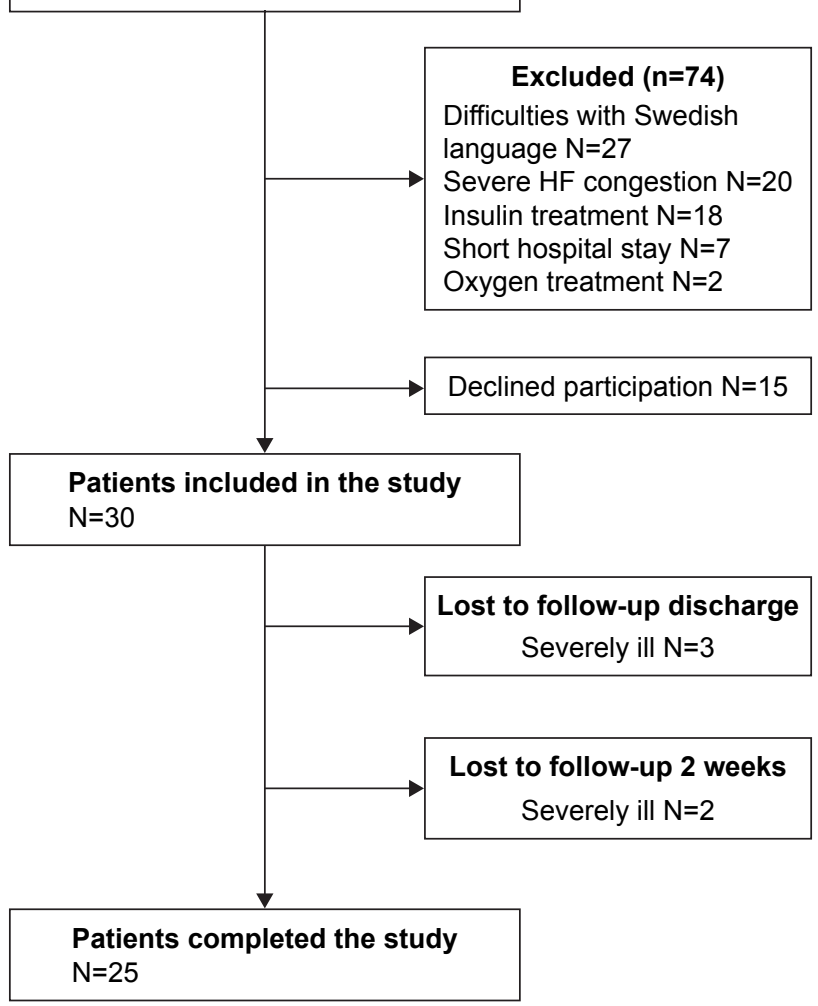

Figure I Flowchart of patients in the study. Abbreviation: $\mathrm{HF}$, heart failure. 
At admission to hospital, the included patients $(n=30)$ had a mean (SD) age of 81 (7) years, and 14 (47\%) were women (Table 1). The mean LVEF of the patients was 37\% (12\%). All patients were prescribed diuretics (dose 30-250 mg/day/ patient; mean dose $77 \mathrm{mg}$ /day) and 23 (77\%) were prescribed beta blockers. Most patients $(n=28,93 \%)$ were NYHA functional class III at the time of admission, and 2 (7\%) were class IV. At the admission, 12 patients (40\%) reported being depressed and $15(50 \%)$ reported being anxious. Nine (30\%) patients were on fluid restriction (Table 1). The median thirst intensity was 39 (14-59) $\mathrm{mm}$ and thirst distress scores 22 (17-28) (Table 2).

Table I Characteristics of the study sample at time of hospital admission

\begin{tabular}{|c|c|}
\hline Characteristics & $(\mathrm{N}=\mathbf{3 0})$ \\
\hline \multicolumn{2}{|l|}{ Demographic and clinical data } \\
\hline Women, n (\%) & $14(47)$ \\
\hline Age, years & $8 I \pm 7$ \\
\hline Cohabiting, n (\%) & $16(53)$ \\
\hline Length of hospital stay, days & $6(4-9)$ \\
\hline LVEF, \% & $37 \pm 12$ \\
\hline $\mathrm{BMI}, \mathrm{kg} / \mathrm{m}^{2}$ & $26 \pm 6$ \\
\hline NYHA, class III, n (\%) & $28(93)$ \\
\hline NYHA, class IV, n (\%) & $2(7)$ \\
\hline P/NT-proBNP, ng/L & $5,350(3,380-13,200)$ \\
\hline $\mathrm{P} /$ sodium, $\mathrm{mmol} / \mathrm{L}$ & $139 \pm 3$ \\
\hline P/urea, mmol/L & $9(8-12)$ \\
\hline P/creatinine, $\mu \mathrm{mol} / \mathrm{L}$ & $103(83-124)$ \\
\hline S/osmolality, mosmol/kg & $30 I \pm 5$ \\
\hline Systolic blood pressure, $\mathrm{mmHg}$ & $135 \pm 29$ \\
\hline Diastolic blood pressure, $\mathrm{mmHg}$ & $75 \pm 13$ \\
\hline \multicolumn{2}{|l|}{ Cardiac comorbidities } \\
\hline Hypertension, n (\%) & $20(67)$ \\
\hline Atrial fibrillation, $\mathrm{n}(\%)$ & $18(60)$ \\
\hline Ischemic disease, n (\%) & II (37) \\
\hline \multicolumn{2}{|l|}{ Non-cardiac comorbidities } \\
\hline COPD, n (\%) & $5(17)$ \\
\hline Stroke, n (\%) & $5(17)$ \\
\hline Malignancy, n (\%) & $3(10)$ \\
\hline Diabetes type 2, n (\%) & $2(7)$ \\
\hline \multicolumn{2}{|l|}{ Non-pharmacological treatment } \\
\hline Fluid restriction, $\mathrm{n}(\%)$ & $9(30)$ \\
\hline \multicolumn{2}{|l|}{ Pharmacological treatment } \\
\hline Beta blocker, n (\%) & $23(77)$ \\
\hline Angiotensin-converting enzyme, $\mathrm{n}(\%)$ & $13(43)$ \\
\hline Angiotensin receptor blocker, $\mathrm{n}(\%)$ & $2(7)$ \\
\hline Mineralocorticoid receptor antagonist, n (\%) & $3(10)$ \\
\hline Furosemide, n (\%) & $30(100)$ \\
\hline Omeprazole, n (\%) & $9(30)$ \\
\hline Opioid, n (\%) & I (3) \\
\hline Antidepressant, n (\%) & I (3) \\
\hline
\end{tabular}

Note: Data are mean $( \pm S D)$, median (IQR), or number $(\%)$ of patients.

Abbreviations: BMI, body mass index; IQR, interquartile range; LVEF, left ventricular ejection fraction; NT-proBNP, N-terminal prohormone brain natriuretic peptide; NYHA, New York Heart Association; P, plasma; S, serum.

\section{Trajectories of thirst intensity and distress by the high and low intensity and distress groups}

The mean of thirst intensity was significantly different between the high intensity and the low intensity groups at the admission ( $59 \mathrm{~mm}$ vs $16 \mathrm{~mm}, P<0.001$ ). Trajectory of the thirst intensity was significantly different for the two groups from admission to 4-weeks follow up (Time* Group interaction $=-8.9, P=0.005$ ) (Table 3 ). As time passed, thirst intensity was decreased for the high intensity group, whereas thirst intensity was increased for the low intensity group (Figure 2).

Although there was a mean difference between the high and low thirst distress groups at admission, the trajectory of thirst distress was not significantly different between groups over time from admission to 4 weeks after discharge. (Time* Group interaction $=-0.7, P=0.460)$ (Figure 2).

\section{Trajectories of thirst intensity and distress by patients' factors}

At the admission, the depressed group reported higher level of thirst intensity than those who were not depressed (Table 4, Figure 3). The trajectories of thirst intensity and distress for both groups were not significantly different from the admission to 4 weeks after discharge but the group difference in intensity and distress remained over time. Women reported significantly higher level of thirst distress than men at the admission and the group difference in thirst distress remained over time (Figure 3). However, there was no difference in trajectory of thirst intensity or distress between men and women over time (Table 4). The fluid restriction group had higher level of thirst distress than the no-fluid restriction group at the admission $(P=0.013)$ (Figure 3$)$. However, the trajectory of thirst distress was not significantly different between 2 groups. For thirst intensity, there was no group or trajectory difference.

There was no group difference, time effect, or difference in the trajectory of thirst intensity and distress between the high and low anxiety groups, between the young and old age groups, between the high and low BMI groups, and between the high and low urea groups (Table 4).

\section{Discussion}

To our knowledge this is the first study examining trajectories of thirst intensity and distress in patients with HF in a longitudinal observation study from hospital admission to 4 weeks follow-up at home. First of all, we found that HF 
Table 2 Thirst intensity and distress from hospital admission to 4 weeks follow-up after hospital discharge in patients with heart failure

\begin{tabular}{lllll}
\hline Variable & $\begin{array}{l}\text { Admission } \\
(\mathbf{n}=\mathbf{3 0})\end{array}$ & $\begin{array}{l}\text { Discharge } \\
(\mathbf{n}=\mathbf{2 7})\end{array}$ & $\begin{array}{l}\mathbf{2} \text { weeks follow-up } \\
(\mathbf{n = 2 5 )}\end{array}$ & $\begin{array}{l}\mathbf{4} \text { weeks follow-up } \\
(\mathbf{n}=\mathbf{2 5})\end{array}$ \\
\hline $\begin{array}{l}\text { Thirst intensity } \\
\text { VAS, 0-100 mm }\end{array}$ & $39(14-59)$ & $36(22-53)$ & $42(17-5 \mid)$ & $34(18-57)$ \\
$\begin{array}{l}\text { Thirst distress } \\
\text { score, 9-45 }\end{array}$ & $22(17-28)$ & $21(15-26)$ & $18(13-28)$ & $20(12-26)$
\end{tabular}

Note: Data is median (IQR).

Abbreviations: IQR, interquartile range; VAS, visual analog scale.

patients with initially high thirst intensity at admission to hospital decreased their thirst over time, in contrast, patients with initially low thirst intensity increased their thirst over time. We also found that patients who were admitted to the hospital with high thirst distress continued to have high thirst distress over time. Patients with fluid restriction and patients who were feeling depressed, had higher level of thirst distress over time than those who did not have fluid restriction or feeling depressed.

Thirst intensity changed over time in patients who were admitted to hospital with high and low thirst intensity levels. From a physiological view, the thirst sensation is to ensure behavior to drink water, and it is primarily regulated by the body fluid osmolality and changes in plasma volume..$^{23}$ Patients who do not drink enough, for example, if they have fluid restriction, may be dehydrated and therefore, experience higher thirst intensity. The different changes of thirst intensity as seen in patients in the 2 groups in this study, may be related to different body hydration states from hospital admission to 4 weeks after discharge. Diuretics are also one possible cause for increased thirst. ${ }^{1}$ Tolvaptan, a selective vasopressin V2 receptor blocker antagonist, ${ }^{1}$ has been

Table 3 Trajectories of thirst intensity and distress for patients with low and high levels of thirst groups at hospital admission

\begin{tabular}{|c|c|c|c|c|c|}
\hline \multirow[t]{2}{*}{ Factor } & \multirow[t]{2}{*}{ Parameter } & \multicolumn{3}{|l|}{$95 \% \mathrm{Cl}$} & \multirow[t]{2}{*}{$P$-value } \\
\hline & & Estimate & Lower & Upper & \\
\hline \multirow[t]{4}{*}{ Thirst intensity } & Intercept $\mathrm{t}^{\mathrm{a}}$ & 23.6 & 17.6 & 29.7 & $<0.00$ I \\
\hline & Time $^{b}$ & 4.4 & 0.1 & 8.6 & 0.045 \\
\hline & Group ${ }^{c}$ & 27.4 & 18.7 & 36.1 & $<0.001$ \\
\hline & Time* Group ${ }^{d}$ & -8.9 & -15.0 & -2.8 & 0.005 \\
\hline \multirow[t]{4}{*}{ Thirst distress } & Intercept $t^{\mathrm{a}}$ & 15.8 & 13.5 & 18.0 & $<0.00 \mathrm{I}$ \\
\hline & Time $^{\mathrm{b}}$ & -0.5 & -1.9 & 0.9 & 0.491 \\
\hline & Group ${ }^{c}$ & 11.6 & 8.4 & 14.8 & $<0.00 \mathrm{I}$ \\
\hline & Time* Group ${ }^{d}$ & -0.7 & -2.7 & 1.2 & 0.460 \\
\hline
\end{tabular}

Notes: antercept value, the level of thirst for the low thirst group at time zero. ${ }^{\mathrm{b}}$ Time estimate, the change in thirst in the low thirst group over 4 follow-up times. 'Group estimate, thirst difference between the low and high thirst groups at time zero. ${ }^{\mathrm{d}}$ Time* Group interaction estimate, the difference in thirst change between the low and high thirst groups. reported to increase thirst in patients with HF, but none of the patients in our study were prescribed this drug. All patients in this study were prescribed diuretics with different doses at admission and for the majority, the dose remained the same during the follow-up. Similar thirst intensity changes, as in our study, were seen in a study in hospitalized decompensated HF patients who were followed up 1 month after hospital discharge in a randomized controlled study investigating the effects of fluid restriction..$^{16}$ The results of our study could also be explained by the regression to the mean.

Patients who reported high thirst distress on admission to the hospital continued to have high thirst distress over time in this study. This confirms our previous findings, in which a majority of patients with HF had temporary thirst, but the likelihood of experiencing thirst over time was dependent on whether thirst was reported at the first measurement. ${ }^{8}$ Patients with persistent thirst need to be identified and might be in need of greater involvement by clinicians. ${ }^{1,2,13}$

Having a fluid restriction was associated with higher level of thirst distress trajectory in this study. Restricting fluid in patients with HF is based on logical reasoning, to relieve congestion and HF symptoms, such as dyspnea and edema. ${ }^{24,25}$ However, no convincing evidence is found for the standard prescription of fluid restriction for all patients with HF. ${ }^{26}$ The negative effect of fluid restriction on thirst distress is supported in a study in which patients with HF had increased thirst distress over time while having prescribed a fluid restriction, even though the patients received education and behavioral strategies to manage the restriction. ${ }^{13}$ Suffering from thirst caused by fluid restriction should be seriously considered, and such a restriction should only be prescribed in patients who can truly benefit from it. ${ }^{26}$ According to guidelines, fluid restriction is not recommended for all patients with $\mathrm{HF} .{ }^{24-27} \mathrm{~A}$ temporary fluid restriction can be beneficial for patients with HF who have fluid overload, severe edema and/or ascites and/or with hyponatremia, in order to relieve congestion and symptoms. ${ }^{24-27} \mathrm{~A}$ tailored fluid restriction 

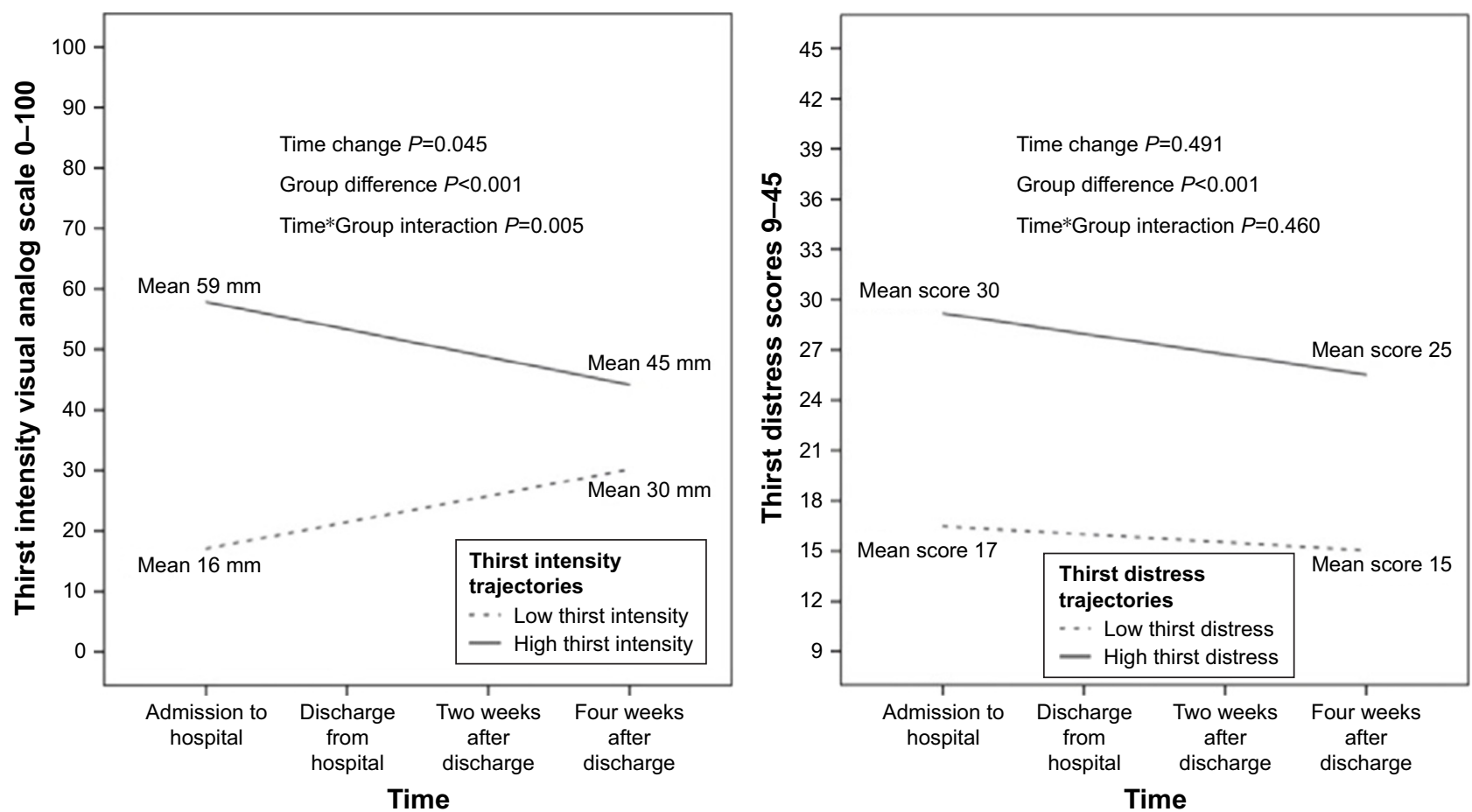

Figure 2 Trajectories of thirst intensity and distress in HF patients admitted to hospital with low and high thirst intensity and distress. Abbreviation: HF, heart failure.

based on body weight ( $30 \mathrm{~mL} / \mathrm{kg}$ per day) seems to be most reasonable and has the least effect on thirst. ${ }^{14,15,26}$

For patients who need a fluid restriction, clinicians should help to manage thirst distress. There are no evidence-based interventions to relieve thirst distress, but in practice, concrete advice has been given, such as distributing fluid intake evenly throughout the day ${ }^{28}$ and sucking on ice cubes or peppermint. $^{5}$

We also found that psychological distress, such as being depressed, was associated with trajectory of thirst intensity. Patients who were feeling depressed had high thirst intensity over time, compared with those who were not feeling depressed. Antidepressant medication, which is associated with thirst, ${ }^{29}$ was prescribed to only 1 patient in the present study. About $30 \%$ of all HF patients are estimated to have depressive symptoms. ${ }^{30}$ Previous studies have shown that stress, measured with the stress-related biomarker cortisol, is increased in patients with high thirst. ${ }^{9}$ HF patients with high thirst have also reported feeling more depressed and anxious. ${ }^{7-9}$ The mechanism between psychological distress and thirst can be the high level of sympathetic activity that is seen in patients with HF, as well as the stressful life situations HF patients are coping with. Patients with HF have various symptoms, which often do not occur alone. Clinicians need to follow a patient-centered approach and should consider thirst as part of the patient's overall troublesome symptoms.

Finally, we found that women had a higher level of thirst distress over time than men. This is not consistent with a previous finding, in which men had been identified to have a higher potential risk for persistent thirst. ${ }^{8}$ In healthy persons, no difference has been reported in thirst between men and women. ${ }^{31}$ However, previous research has shown that women tend to have more symptoms related to HF, and they experience higher distress levels of fatigue, anxiety, and feeling depressed, compared with men. ${ }^{32-36}$

The strength of this study was the use of growth modeling, as it has advantages over the more traditional data analytic approach with repeated-measures ANOVA; for example, missing data values do not cause a given subject to be dropped. ${ }^{20,22,37}$ Moreover, the linear mixed analysis has sufficient power to detect group differences in a moderate or small sample size. ${ }^{37}$ Other strengths of this study are that it includes longitudinal data collected at 4 time points. This study has several limitations. We assessed patients feeling depressed and anxious using a 2-item question, not standardized or valid questionnaires that may capture a more comprehensive phenomenon of depression or anxiety. Thus, the findings should be generalized with caution and should not be interpreted 
Table 4 Trajectories of thirst intensity and distress by patients' factors

\begin{tabular}{|c|c|c|c|c|c|c|c|c|c|}
\hline \multirow[t]{3}{*}{ Factor } & \multirow[t]{3}{*}{ Parameter } & \multicolumn{3}{|c|}{ Thirst intensity } & \multirow[t]{3}{*}{$P$-value } & \multicolumn{3}{|c|}{ Thirst distress } & \multirow[t]{3}{*}{$P$-value } \\
\hline & & \multicolumn{3}{|l|}{$95 \% \mathrm{Cl}$} & & \multicolumn{3}{|l|}{$95 \% \mathrm{Cl}$} & \\
\hline & & Estimate & Lower & Upper & & Estimate & Lower & Upper & \\
\hline \multirow[t]{4}{*}{ Fluid restriction } & Intercept $\mathrm{t}^{\mathrm{a}}$ & 35.4 & 26.4 & 44.4 & $<0.001$ & 19.7 & 16.6 & 22.9 & $<0.001$ \\
\hline & Time $^{\mathrm{b}}$ & 1.5 & -4.0 & 7.0 & 0.591 & -1.0 & -2.7 & 0.7 & 0.240 \\
\hline & Group ${ }^{c}$ & 4.8 & -5.4 & 15.0 & 0.355 & 4.1 & 0.9 & 7.2 & 0.013 \\
\hline & Time* Group $^{d}$ & -4.9 & -12.1 & 2.4 & 0.187 & -0.5 & -2.7 & 1.7 & 0.633 \\
\hline \multirow[t]{4}{*}{ Feeling depressed } & Intercept & 33.8 & 26.8 & 40.7 & $<0.001$ & 21.6 & 18.8 & 24.4 & $<0.001$ \\
\hline & Time & -0.3 & -4.7 & 4.0 & 0.874 & -0.7 & -2.1 & 0.6 & 0.287 \\
\hline & Group & 11.6 & 1.7 & 21.5 & 0.023 & 0.4 & -2.7 & 3.6 & 0.781 \\
\hline & Time* Group & 2.1 & -5.3 & 9.6 & 0.570 & 0.003 & -2.3 & 2.3 & 0.998 \\
\hline \multirow[t]{4}{*}{ Feeling anxious } & Intercept & 35.6 & 28.3 & 42.9 & $<0.00$ I & 21.4 & 18.5 & 24.2 & $<0.001$ \\
\hline & Time & 0.4 & -4.0 & 4.8 & 0.867 & -0.6 & -2.0 & 0.7 & 0.358 \\
\hline & Group & 3.8 & -5.5 & 13.0 & 0.423 & 1.2 & -1.6 & 3.8 & 0.426 \\
\hline & Time* Group & -0.7 & -8.3 & 6.8 & 0.852 & -0.03 & -2.3 & 2.2 & 0.979 \\
\hline \multirow[t]{4}{*}{ Gender } & Intercept & 40.9 & 30.7 & 51.1 & $<0.001$ & 24.5 & 20.7 & 28.3 & $<0.001$ \\
\hline & Time & -0.2 & -5.7 & 5.3 & 0.938 & -0.8 & -2.6 & 0.8 & 0.318 \\
\hline & Group & -7.4 & -21.2 & 6.4 & 0.284 & -5.2 & -10.4 & -0.07 & 0.047 \\
\hline & Time* Group & -0.08 & -7.5 & 7.4 & 0.984 & 0.2 & -2.1 & 2.5 & 0.866 \\
\hline \multirow[t]{4}{*}{ Age } & Intercept & 41.2 & 26.7 & 55.6 & $<0.001$ & 21.0 & 15.4 & 26.6 & $<0.001$ \\
\hline & Time & 2.4 & -5.2 & 10.0 & 0.538 & 0.7 & -1.6 & 3.1 & 0.528 \\
\hline & Group & -5.6 & -22.1 & 11.0 & 0.489 & 0.9 & -5.5 & 7.3 & 0.772 \\
\hline & Time* Group & -3.5 & -12.2 & 5.2 & 0.424 & -2.0 & -4.7 & 0.7 & 0.147 \\
\hline \multirow[t]{4}{*}{ Body mass index } & Intercept & 36.6 & 27.9 & 45.2 & $<0.001$ & 21.1 & 17.9 & 24.3 & $<0.001$ \\
\hline & Time & -0.7 & -5.6 & 4.2 & 0.790 & -0.9 & -2.4 & 0.6 & 0.255 \\
\hline & Group & 0.8 & -11.4 & 13.0 & 0.894 & 1.4 & -2.8 & 5.7 & 0.496 \\
\hline & Time* Group & 0.8 & -6.6 & 8.3 & 0.823 & 0.3 & -2.0 & 2.6 & 0.773 \\
\hline \multirow[t]{4}{*}{ Plasma urea } & Intercept & 37.1 & 28.2 & 45.9 & $<0.001$ & 21.3 & 17.8 & 24.9 & $<0.001$ \\
\hline & Time & -0.9 & -7.2 & 5.4 & $0.78 \mathrm{I}$ & -0.1 & -1.5 & 1.3 & 0.880 \\
\hline & Group & 5.6 & -4.9 & 16.0 & 0.290 & $\mathrm{I} .4$ & -0.9 & 3.6 & 0.226 \\
\hline & Time* Group & 0.8 & -7.8 & 9.4 & 0.853 & -0.4 & -2.3 & 1.5 & 0.676 \\
\hline
\end{tabular}

Notes: antercept value, the level of thirst for the control group at time zero. 'bime estimate, the change in thirst in the control group over 4 follow-up times. ${ }^{~} \mathrm{Group}$ estimate, thirst difference between the groups at time zero. ${ }^{\mathrm{D}} \mathrm{Time}{ }^{*} \mathrm{Group}$ interaction estimate, the difference in thirst change between the groups.

as clinical depression or anxiety. Another limitation in the study is that we did not collect individual information of the patients' habitual drinking behaviors. In fact, if all individuals have habitual drinking behavior from admission to 4 weeks after discharge, our study finding may be more significant because having habitual drinking behavior may minimize changes of drinking amounts within subject (individuals) over time. Due to a small sample size of this study, there is limited generalizability in the HF population.

Implications for practice at hospital admission, nurses are recommended to: (a) screen for and identify patients with $\mathrm{HF}$ with increased thirst intensity and distress, with fluid restriction, and feeling depressed. Although women were more likely to have increased thirst in this study, both men and women should be asked about thirst. Before patient's discharge: (b) educate patients about thirst, what can cause thirst, how to monitor thirst, and give solutions how to relieve thirst (eg, sucking ice cubes), (c) evaluate the usefulness of a fluid restriction with a cardiologist, (d) consult a cardiologist if the patient feels depressed, and (e) schedule a follow-up visit for patients with troublesome thirst to an outpatient HF clinic. A randomized controlled trial is needed to test if an educational program for nurses, using the recommendations, is effective to decrease thirst intensity and distress in patients with HF.

\section{Conclusion}

Levels of thirst intensity and distress (high and low) in patients with $\mathrm{HF}$ at the admission were critical in predicting the trajectory of thirst intensity and distress after discharge to their home. Being depressed, having fluid restriction and gender were also associated with trajectories of thirst intensity or distress. Engaging clinicians in regular thirst-monitoring is the first step to recognizing increased thirst intensity and distress and prompting the process toward management strategies to alleviate thirst in HF patients. 


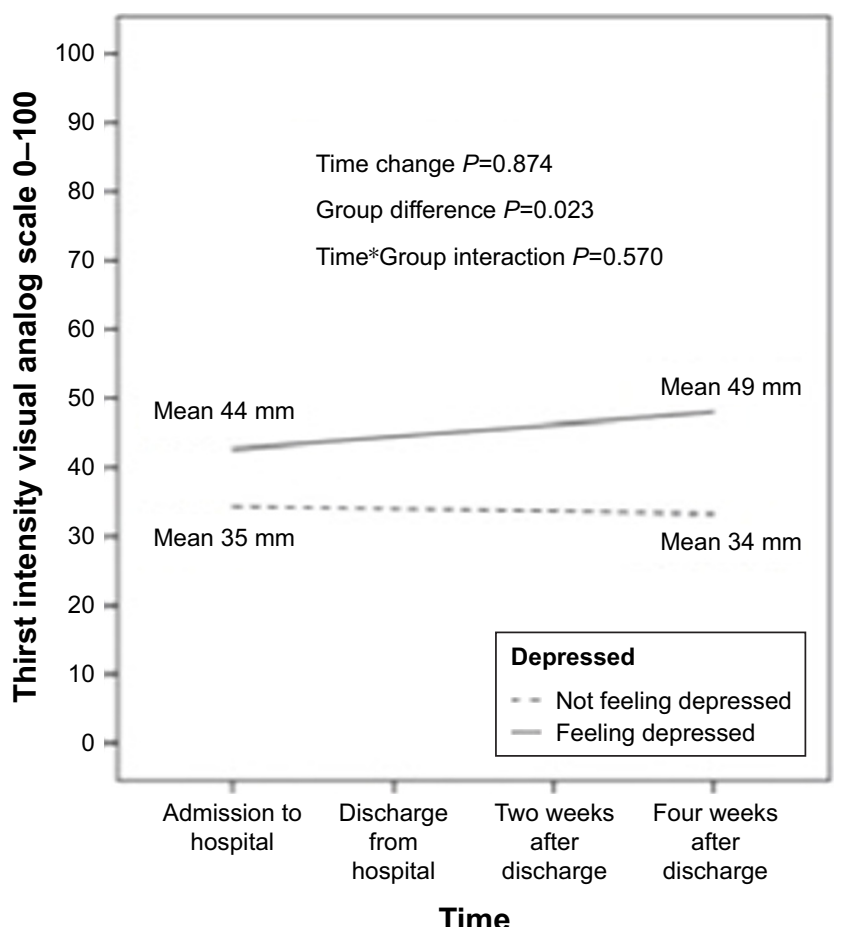

Time

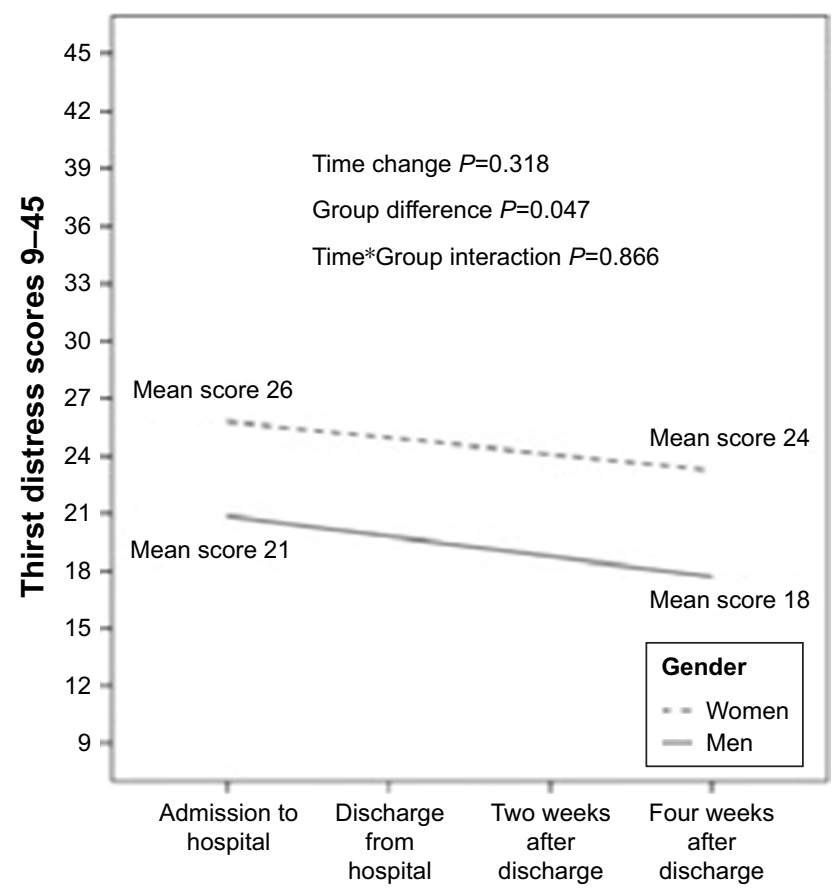

Time

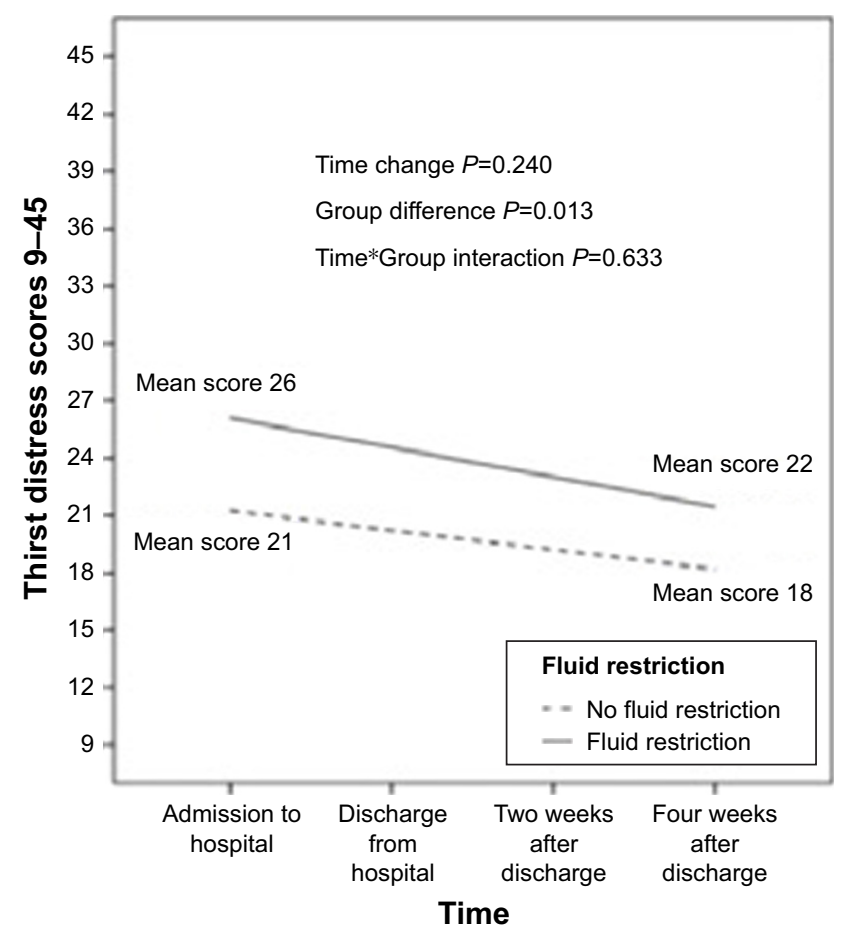

Figure 3 Trajectories of thirst intensity and distress by the patient factors of feeling depressed, gender, and fluid restriction in HF patients. Abbreviation: $\mathrm{HF}$, heart failure.

\section{Acknowledgments}

The authors are grateful to the patients who participated in this study. They also acknowledge Pia Jonsson for her help with data collection, and the cardiologists at the Department of Internal Medicine for performing the echocardiography.

\section{Disclosure}

The authors report no conflicts of interest in this work.

\section{References}

1. Waldréus N, Hahn RG, Jaarsma T. Thirst in heart failure: a systematic literature review. Eur J Heart Fail. 2013;15(2):141-149. 
2. Reilly CM, Meadows K, Dunbar S, Culler S, Smith A. Thirst and QOL in persons with heart failure. Heart \& Lung: The Journal of Acute and Critical Care. 2010;39(4):353.

3. Nordgren L, Sörensen S. Symptoms experienced in the last six months of life in patients with end-stage heart failure. Eur J Cardiovasc Nurs. 2003;2(3):213-217.

4. Brännström M, Ekman I, Norberg A, Boman K, Strandberg G. Living with severe chronic heart failure in palliative advanced home care. Eur J Cardiovasc Nurs. 2006;5(4):295-302.

5. van der Wal MH, Jaarsma T, Moser DK, van Gilst WH, van Veldhuisen DJ. Qualitative examination of compliance in heart failure patients in The Netherlands. Heart Lung. 2010;39(2):121-130.

6. Falk S, Wahn AK, Lidell E. Keeping the maintenance of daily life in spite of chronic heart failure. A qualitative study. Eur J Cardiovasc Nurs. 2007;6(3):192-199.

7. Waldréus N, Sjöstrand F, Hahn RG. Thirst in the elderly with and without heart failure. Arch Gerontol Geriatr. 2011;53(2):174-178.

8. Waldréus $\mathrm{N}$, van der Wal MH, Hahn RG, van Veldhuisen DJ, Jaarsma T. Thirst trajectory and factors associated with persistent thirst in patients with heart failure. J Card Fail. 2014;20(9):689-695.

9. Waldréus N, Hahn RG, Lyngå P, van der Wal MH, Hägglund E, Jaarsma T. Changes in Thirst Intensity During Optimization of Heart Failure Medical Therapy by Nurses at the Outpatient Clinic. J Cardiovasc Nurs. 2016;31(5):E17-E24.

10. Toto KH. Regulation of plasma osmolality: thirst and vasopressin. Crit Care Nurs Clin North Am. 1994;6(4):661-674.

11. Welch JL. Development of the thirst distress scale. Nephrol Nurs J. 2002;29(4):337-342.

12. Ambrosy AP, Fonarow GC, Butler J, et al. The global health and economic burden of hospitalizations for heart failure: lessons learned from hospitalized heart failure registries. $J$ Am Coll Cardiol. 2014;63(12):1123-1133

13. Reilly CM, Higgins M, Smith A, Culler SD, Dunbar SB. Isolating the benefits of fluid restriction in patients with heart failure: A pilot study. Eur J Cardiovasc Nurs. 2015;14(6):495-505.

14. Holst M, Strömberg A, Lindholm M, Willenheimer R. Liberal versus restricted fluid prescription in stabilised patients with chronic heart failure: result of a randomised cross-over study of the effects on healthrelated quality of life, physical capacity, thirst and morbidity. Scand Cardiovasc J. 2008;42(5):316-322.

15. Holst M, Strömberg A, Lindholm M, Willenheimer R. Description of self-reported fluid intake and its effects on body weight, symptoms, quality of life and physical capacity in patients with stable chronic heart failure. J Clin Nurs. 2008;17(17):2318-2326.

16. Aliti GB, Rabelo ER, Clausell N, Rohde LE, Biolo A, Beck-da-Silva L. Aggressive fluid and sodium restriction in acute decompensated heart failure: a randomized clinical trial. JAMA Intern Med. 2013;173(12):1058-1064.

17. Holst M, Strömberg A, Lindholm M, Uden G, Willenheimer R. Fluid restriction in heart failure patients: is it useful? The design of a prospective, randomised study. Eur J Cardiovasc Nurs. 2003;2(3):237-242.

18. Jaarsma T, Waldréus N, van der Wal M, Kato Perkiö N. Measuring thirst in patients with heart failure: The Thirst Distress Scale for patients with HF is ready to use. Circulation. 2016;134(Suppl 1):A16876.

19. Waldréus N, Jaarsma T, van der Wal MH, Kato Perkiö N. Development and psychometric evaluation of the Thirst Distress Scale for patients with heart failure. Eur J Cardiovasc Nurs. 2018;17(3):226-234.
20. Hesser H. Modeling individual differences in randomized experiments using growth models: Recommendations for design, statistical analysis and reporting of results of internet interventions. Internet Interv. 2015;2(2):110-120.

21. Field AP. Discovering statistics using IBM SPSS statistics. 4th. London: Sage publications; 2013.

22. Enders CK, Tofighi D. Centering predictor variables in cross-sectional multilevel models: a new look at an old issue. Psychol Methods. 2007;12(2):121-138.

23. Thornton SN. Thirst and hydration: physiology and consequences of dysfunction. Physiol Behav. 2010;100(1):15-21.

24. Ponikowski P, Voors AA, Anker SD, et al. ESC Guidelines for the diagnosis and treatment of acute and chronic heart failure: The Task Force for the diagnosis and treatment of acute and chronic heart failure of the European Society of Cardiology (ESC). Developed with the special contribution of the Heart Failure Association (HFA) of the ESC Eur J Heart Fail. 2016;18(8):891-975.

25. Yancy CW, Jessup M, Bozkurt B, et al. 2013 ACCF/AHA Guideline for the Management of Heart Failure: a report of the American College of Cardiology Foundation/American Heart Association Task Force on Practice Guidelines. J Am Coll Cardiol. 2013;62(16):e147-e239.

26. Johansson P, van der Wal MH, Strömberg A, Waldréus N, Jaarsma T. Fluid restriction in patients with heart failure: how should we think? Eur J Cardiovasc Nurs. 2016;15(5):301-304.

27. Lainscak M, Blue L, Clark AL, et al. Self-care management of heart failure: practical recommendations from the Patient Care Committee of the Heart Failure Association of the European Society of Cardiology. Eur J Heart Fail. 2011;13(2):115-126.

28. Philipson H, Ekman I, Forslund HB, Swedberg K, Schaufelberger M. Salt and fluid restriction is effective in patients with chronic heart failure. Eur J Heart Fail. 2013;15(11):1304-1310.

29. Gupta A, Epstein JB, Sroussi H. Hyposalivation in elderly patients. $J$ Can Dent Assoc. 2006;72(9):841-846.

30. Hare DL, Toukhsati SR, Johansson P, Jaarsma T. Depression and cardiovascular disease: a clinical review. Eur Heart J. 2014;35(21):1365-1372.

31. Armstrong LE, Johnson EC, Mckenzie AL, Ellis LA, Williamson KH Endurance Cyclist Fluid Intake, Hydration Status, Thirst, and Thermal Sensations: Gender Differences. Int J Sport Nutr Exerc Metab. 2016;26(2):161-167.

32. Lee KS, Song EK, Lennie TA, et al. Symptom clusters in men and women with heart failure and their impact on cardiac event-free survival. J Cardiovasc Nurs. 2010;25(4):263-272.

33. Barnes S, Gott M, Payne S, et al. Prevalence of symptoms in a community-based sample of heart failure patients. $J$ Pain Symptom Manage. 2006;32(3):208-216.

34. Gottlieb SS, Khatta M, Friedmann E, et al. The influence of age, gender, and race on the prevalence of depression in heart failure patients. $J \mathrm{Am}$ Coll Cardiol. 2004;43(9):1542-1549.

35. Ekman I, Ehrenberg A. Fatigue in chronic heart failure - does gender make a difference? Eur J Cardiovasc Nurs. 2002;1(1):77-82.

36. Hägglund L, Boman K, Olofsson M, Brulin C. Fatigue and healthrelated quality of life in elderly patients with and without heart failure in primary healthcare. Eur J Cardiovasc Nurs. 2007;6(3):208-215.

37. Fan X. Power of Latent Growth Modeling for Detecting Group Differences in Linear Growth Trajectory Parameters. Structural Equation Modeling: A Multidisciplinary Journal. 2003;10(3):380-400.
Patient Preference and Adherence

\section{Publish your work in this journal}

Patient Preference and Adherence is an international, peer-reviewed, open access journal that focuses on the growing importance of patient preference and adherence throughout the therapeutic continuum. Patient satisfaction, acceptability, quality of life, compliance, persistence and their role in developing new therapeutic modalities and compounds to optimize

\section{Dovepress}

clinical outcomes for existing disease states are major areas of interest for the journal. This journal has been accepted for indexing on PubMed Central. The manuscript management system is completely online and includes a very quick and fair peer-review system, which is all easy to use. Visit http://www. dovepress.com/testimonials.php to read real quotes from published authors. 